\title{
Therapeutic Management in the Idiopathic Ventricular Fibrillation: Is there Still a Place for Pharmacological Treatment?
}

\section{Osmar Antonio Centurión ${ }^{1,2 *}$}

${ }^{1}$ Cardiology Department, Clinical Hospital, Asunción National University, Paraguay

${ }^{2}$ Division of Arrhythmia and Electrophysiology, Sanatorio Migone-Battilana, Asunción, Paraguay

\begin{abstract}
Sudden cardiac death in the truly normal heart is an uncommon occurrence. The majority of patients without apparent structural heart disease who died suddenly do not actually have "normal" hearts. Idiopathic ventricular fibrillation (IVF) is an uncommon disease of unknown etiology that manifests as syncope, cardiac arrest or seizures caused by rapid polymorphic ventricular tachycardia (VT) or VF in the absence of structural heart disease or identifiable channelopathy. Usually during an arrhythmic storm, it is relatively easy to diagnose IVF in a cardiac arrest survivor when the onset of spontaneous polymorphic VT/VF can be recorded, and this shows initiation of polymorphic VT/VF by very short coupled ventricular ectopy. IVF is essentially a diagnosis by exclusion. However, typical clinical and electrophysiological characteristics present in some patients often allows for a positive diagnosis. Since the rate of recurrence of malignant ventricular arrhythmias in IVF is unacceptably high in the absence of therapy, once a diagnosis of IVF is made, some form of therapy is mandatory. Therapy may include ICD implantation, drug therapy, radiofrequency catheter ablation of the triggering focus or combinations of the above. This article will discuss the role of pharmacological treatment in the therapeutic management of IVF. Is there still a place for pharmacological treatment in IVF? Yes, there is still a place for pharmacological treatment in the therapeutic armamentarium of IVF in carefully selected, individually well documented patients.
\end{abstract}

Keywords: Idiopathic ventricular fibrillation; Pharmacological therapy; Implantable cardiovertorde fibrillator; Radiofrequency catheter ablation

\section{Introduction}

Idiopathic ventricular fibrillation (IVF) is a rare disorder encountered in only $3 \%$ to $9 \%$ of cases of out-of-hospital ventricular fibrillation (VF) not related to an acute coronary syndrome. The majority of patients without apparent structural heart disease who died suddenly do not actually have "normal" hearts. In a small number of cases of survivors of sudden cardiac death (SCD), despite extensive clinical evaluation, no underlying structural heart disease can be found. SCD in the truly normal heart is an uncommon occurrence. Most individuals suffering from SCD become unconscious within seconds to minutes as a result of insufficient cerebral blood flow. There are usually no premonitory symptoms or signs. Although the risks of SCD are higher in patients with structural heart disease, and the underlying pathophysiology for the majority of these deaths is due to coronary artery disease, SCD events also occur in individuals with apparently normal hearts [1-5].

In the past decade, increasing attention has focused on this group of survivors of out-of-hospital cardiac arrest, which is also known as IVF [1-3]. The etiology of many of these deaths was unknown and deemed "idiopathic." However, subsequent discoveries have identified the cause of death in many of these patients. The typical clinical characteristics of IVF were summarized and are stated in the Table 1. The mode of onset of spontaneous arrhythmias in IVF is due to the triggering of rapid polymorphic VT/VF by premature ventricular contractions (PVCs) with very short coupling intervals (R-on-T phenomenon). Haissaguerre et al demonstrated that the short-coupled PVCs triggering VF in this disease are very-early PVCs originating from Purkinje fibers [6]. The differential diagnosis of IVF included the following arrhythmia-disorders: the long QT syndrome [7-9], the catecholamine sensitive polymorphic VT (CPVT) [10], and the syndrome of nocturnal sudden death of South East Asia [11]. However, in 1992, the Brugada brothers described patients with otherwise IVF who had a peculiar electrocardiogram showing right bundle branch block with persistent ST-segment elevation in the right precordial leads [12]. It soon became evident that more than $20 \%$ of patients thought until then to have IVF had the Brugada syndrome [13]. Moreover, in 1997 it became clear that the syndrome of unexplained nocturnal sudden death in South East Asia was in fact, an endemic manifestation of the Brugada syndrome in Asia [14]. More recently, patients with the congenital short QT syndrome [15,16] proved to have inducible [15], and spontaneous $[17,18]$ ventricular arrhythmias indistinguishable from those of IVF patients. Therapy for IVF patients may include ICD implantation, drug therapy, radiofrequency catheter ablation of the triggering focus or combinations of the above. Although ICD implantation is the treatment of choice in IVF, in this article, it will be discussed the role of pharmacological treatment in the therapeutic management of IVF. Is there still a place for pharmacological treatment in IVF?

\begin{tabular}{|c|l|}
\hline S No & Clinical features of Idiopathic Ventricular Fibrillation \\
\hline 1 & The onset of symptoms during early adulthood in both genders. \\
\hline 2 & $\begin{array}{l}\text { The relatively high incidence of arrhythmic storms with clusters of VF } \\
\text { episodes. }\end{array}$ \\
\hline 3 & The high inducibility rate of VF with programmed ventricular stimulation. \\
\hline 4 & Adequate response to quinidine therapy in EPS-guided patients. \\
\hline
\end{tabular}

Table 1: Clinical features of Idiopathic Ventricular Fibrillation.

*Corresponding author: Osmar A. Centurión, Faculty of Medical Sciences, Asunción National University, Trejoy Sanabria 1657, Sajonia, Asunción, Paraguay, Tel: 595-21-421423; Fax: 595-21-421423, E-mail: osmarcenturion@hotmail.com

Received May 30, 2014; Accepted July 22, 2014; Published July 30, 2014

Citation: Centurión OA (2014) Therapeutic Management in the Idiopathic Ventricular Fibrillation: Is there Still a Place for Pharmacological Treatment? J Bioequiv Availab 6: 128-133. doi:10.4172/jbb.1000192

Copyright: @ 2014 Centurión OA. This is an open-access article distributed under the terms of the Creative Commons Attribution License, which permits unrestricted use, distribution, and reproduction in any medium, provided the original author and source are credited. 


\section{Electrophysiological properties in IVF}

Induction of polymorphic VT by programmed ventricular stimulation is often viewed as an artifact or a non-clinical arrhythmia in patients without organic heart disease. In addition, the odds of inducing polymorphic VT or VF are inversely related to the coupling intervals used during programmed ventricular stimulation with extra-stimuli. Therefore, induction of sustained polymorphic VT and VF in patients with a history of cardiac arrest may be clinically relevant. Moreover, the spontaneous arrhythmias leading to cardiac arrest in IVF are indeed polymorphic and are precipitated by PVCs with a short coupling interval. Thus, whenever IVF is suspected following an episode of cardiac arrest, protocols of programmed extra-stimulation using short coupling intervals should be considered. Electrophysiological studies in animals and humans have determined the existence of a vulnerable period in the cardiac cycle, during which a single premature stimulus of appropriate strength can reproducibly induce VF. The most vulnerable phase, as judged from the stimulus strength needed to induce VF, is the upslope of the T wave, but the peak and early phases of the T wave down-slope are also within this vulnerable phase. The clinical $\mathrm{R}$ on $\mathrm{T}$ phenomenon refers to depolarization during this vulnerable period, at a time when there is maximal dispersion of refractoriness in the ventricle, which leads to functional unidirectional block and multiple reentrant waves of VF even in a normal ventricle. Some investigators have reported the presence of fractionated right ventricular potentials during ventricular extra-stimulation in patients with IVF. Conduction block was found responsible for wave front fractionation and re-entry, an important mechanism in proliferation of wave fronts and rotors during VF.

There are some interesting findings that shed some light into the understanding of the mechanism and etiology of IVF. At almost 8 decades after the original description of IVF [1], the etiology of this disorder still remains a mystery. There are some clinical and electrophysiological data which suggest that IVF is a channelopathy. The spontaneous and inducible ventricular arrhythmias of IVF are remarkably similar to those observed in two well-described channelopathies involving hereditary malfunction of sodium channels (Brugada syndrome) [19] or potassium channels (short QT syndromes) [20-22]. Moreover, patients with the Brugada syndrome may have the typical diagnostic electrocardiogram with ST segment elevation in the right precordial leads at some times, but may have normal or near-normal electrocardiograms at other times, making distinction of patients with IVF and Brugada syndrome challenging. In fact, a diagnosis of IVF is not considered definite until the Brugada syndrome with near normal electrocardiogram is excluded by performing a drug-challenge with a sodium-channel blocker, namely, ajmaline [23-25], flecainide [25-27], disopyramide [28] or procainamide [29]. These drugs will worsen any inborn malfunction of sodium channels, augmenting the ST segment elevation in up to $40 \%$ of patients with Brugada syndrome who have a normal electrocardiogram $[19,25,30]$. On the other hand, the fact that only a minority of patients with IVF report a familial history of sudden death [3,31-36] is a strong argument against the role of genetic channelopathies in this disease.

The electrocardiogram of patients with IVF is normal during sinus rhythm. Japanese investigators reported that patients with IVF often have J-point elevation in the inferior leads [37]. Male patients with IVF have a disproportionably high prevalence of relatively short QT [18]. The Tpeak-Tend interval, that is the interval from the summit to the end of the $\mathrm{T}$ wave, which is a marker of the ventricular dispersion of repolarization and arrhythmic risk in the long QT syndromes $[38,39]$ and Brugada syndrome [40-43], is normal in IVF [18]. PVCs only rarely occur in patients with IVF, but when they do, they have varying coupling intervals with some PVCs closely coupled to the preceding complex. There appears to be an inverse relationship between the coupling interval of the PVCs and the risk for malignant arrhythmias with longer bursts of polymorphic VT triggered by PVCs with shorter coupling intervals [32]. There are observations that support the notion that IVF has a focal origin. In this regard, Haissaguerre et al recently proposed that IVF represents a "focal VF" triggered by ectopic beats originating from Purkinje fibers [33]. These Purkinje PVCs are so premature that fall on the vulnerable period of the surrounding ventricular tissue, initiating reentrant VF. Radiofrequency ablation directed to this very early VPC with a recorded Purkinje potential terminated IVF in selected patients. The very-early Purkinje ectopic beats have been demonstrated by intracardiac recordings [33] but the reason for this very-premature focal activity remains to be determined.

Electrophysiological studies performed in patients with IVF demonstrate normal $\mathrm{A}-\mathrm{H}$ and $\mathrm{H}-\mathrm{V}$ intervals, and their ventricular refractory periods are within normal limits $[2,44]$. This is in contrast to patients with Brugada syndrome, who often have prolonged $\mathrm{H}-\mathrm{V}$ interval [12] and patients with short QT syndrome, who invariably have short refractory periods in the atrium and the ventricle $[15,45,46]$. The ventricular arrhythmias induced by programmed ventricular stimulation are invariably of polymorphic morphology, namely polymorphic VT or VF. Induction of monomorphic VT excludes the diagnosis of IVF. This is different in patients with Brugada syndrome who also have primarily VF [47], but rarely have monomorphic VT [48-53]. The inducibility rate is a function of the protocol used during programmed ventricular stimulation. In earlier small studies, $9 \%$ of healthy individuals without documented or suspected spontaneous ventricular arrhythmias had inducible VF when the coupling intervals were limited only by ventricular refractoriness. Moreover, an additional $40 \%$ had inducible non-sustained polymorphic VT and this lead to premature discontinuation of the pacing protocol. Therefore, one must recognize that at least $9 \%$ of healthy individuals will have inducible VF if aggressive protocols of extra-stimulation are utilized [54-56]. On the other hand, as many as $80 \%$ of patients with IVF have inducible VF with aggressive protocols of extra-stimulation consisting of double and triple ventricular extra-stimuli at two right ventricular pacing sites and using repetition of extra-stimulation at the shortest coupling interval that captures the ventricle [44,57]. This very high-inducibility rate suggests that the induction of VF, with aggressive protocols of extrastimulation, is a valid endpoint of programmed ventricular stimulation that then may be used for guiding anti-arrhythmic therapy in patients with IVF.

Recently, using endocardial recordings in patients with IVF at a time when they had frequent spontaneous PVCs and/or bursts of polymorphic VT, the investigators were able to locate the site of origin of these ventricular arrhythmias in 27 patients [32,33]. Successful localization of the site of origin of the ventricular arrhythmias was guided by recording of very early endocardial electrograms and confirmed by abolition of ventricular arrhythmias following radiofrequency ablation of the firing focus. Purkinje potentials were recorded at the site of origin of ventricular arrhythmias in 23 (85\%) out these 27 patients. The Purkinje potentials preceded the local myocardial activation by $11 \pm 5 \mathrm{~ms}$ during sinus rhythm and by $10 \pm 15 \mathrm{~ms}$ during spontaneous PVC [32]. Based on these endocardial recordings, it seems that the arrhythmias in IVF have a focal origin and that the triggering focus is within the Purkinje fibers in the majority of patients. Of note, the firing focus was not within the Purkinje network in only 4 (15\%) 
patients and in all these patients the arrhythmias originated in the right ventricular outflow tract (RVOT). Other sites were also described in detail, Noda and Shimizu recently reported a large series of patients with polymorphic VT/VF originating in the RVOT [41,58].

\section{Prognosis and therapeutic management in IVF}

Among survivors of SCD due to IVF, the reported rate of recurrent VF ranges between 22 and 37 percent at two to four years. Because they have no structural heart disease, these patients have an excellent prognosis for long-term survival if VF is prevented. As a result, such patients are best treated with an ICD. At a mean follow-up of 6 years, more than $40 \%$ of patients have recurrent VF and the risk is higher for those with normal electrocardiograms, that is, after excluding those with possible Brugada syndrome [59]. In a recent series of IVF patients with the exclusion not only of those with Brugada-type electrocardiogram at baseline but also those who developed ST-segment elevation when challenged with sodium channel blockers, the risk for recurrent VF was $39 \%$ at 3 years [34]. Therefore, once a diagnosis of IVF is made, some form of acatheter ablation of the triggering focus or combinations of the above.

Pharmacological therapy: The very first IVF patients were treated with quinidine after multiple episodes of spontaneous polymorphic VT and VF were clearly documented. Both patients had an excellent response. Quinidine may exert its beneficial effects by inhibiting the transient outward potassium current (Ito), thereby restoring electrical homogeneity. In addition, quinidine prolongs ventricular refractoriness, and its anticholinergic effect might contribute to its antiarrhythmic efficacy [1,60-62]. In 1987, the therapy of IVF with EPS-guided quinidine was implemented after observing that VF was easily inducible at the baseline state but no longer inducible after quinidine therapy [2]. Of note, one of the patients included in that original report [43], already completed more than 25 uneventful years of electrophysiologic-guided therapy with amiodarone and quinidine after experiencing arrhythmic storms of VF in the absence of therapy and recurrent arrhythmic syncope on amiodarone alone [62].

In general there is a high recurrence rate with only pharmacological treatment. It was found that the recurrence rate of cardiac arrest was high during drug therapy with amiodarone, beta-blockers or verapamil [3]. The high-rate of arrhythmia recurrence with verapamil is worth noting because that drug was empirically administrated to treat the short-coupled variant of torsade de pointes [4], an entity that probably represents IVF. In contrast, there was no recurrence reported with quinidine [3]. The criteria for quinidine therapy in IVF survivors are stated in Table 2, and may be summarized as follows: Of 34 patients with IVF with aborted sudden cardiac arrest, 26 (80\%) had inducible VF at baseline electrophysiologic study and all but one of them were rendered non-inducible with quinidine. Side effects from quinidine led to discontinuation of quinidine therapy in $14 \%$ of our patients. Although, quinidine therapy was well tolerated in most patients, some presented thrombocytopenia, intolerable diarrhea, esophagitis, allergic reactions, and aggravation of sinus node dysfunction. These side effects usually appeared within the first month and in all instances resolved with drug discontinuation. Nevertheless, 23 patients remained on quinidine therapy without ICD back-up, and all are alive and completely free of arrhythmic symptoms that now exceeds 10 years. It is very important to consider the risks of most anti-arrhythmic drugs with regard to the potential for loss of efficacy or pro-arrhythmia under a number of clinical conditions including hypokalemia, hypomagnesemia, bradycardia, therapy with other agents that alter repolarization, metabolic inhibitors, and changes in myocardial substrate. Nevertheless, it is no longer recommend the empiric use of quinidine for non-inducible patients, a subgroup of patients for whom ICD implantation is mandatory. The excellent response of VF storms in IVF with Brugada syndrome has also been repeatedly reported [6365].

Amiodarone may be used as an alternative therapy during acute episodes of ventricular arrhythmias. During acute amiodarone treatment, rapid intravenous administration blocks fast sodium channels in a use-dependent fashion that is, producing more channel blockade at faster heart rates. It also inhibits norepinephrine release, and blocks L-type calcium channels but does not prolong ventricular refractoriness. Conversely, in oral amiodarone therapy, prolonged ventricular refractory periods are seen over periods ranging from days to weeks [66-68]. Amiodarone has few negative inotropic effects and is safe in patients who have depressed systolic function. Moreover, the incidence of torsades de pointes is low in such patients despite the potential for significant prolongation of the QT interval. Amiodarone can be effective even when other agents have been ineffective. Levine and colleagues [69] examined patients who were refractory to lidocaine, procainamide, and bretylium therapy. When amiodarone was given, $46 \%$ of the patients survived for 24 hours without another episode of VT/VF, and another $12 \%$ responded after taking amiodarone plus another agent. In short-term use of the drug, side effects were rare. Amiodarone is also effective as adjunctive therapy to prevent recurrent ICD shocks [70]. Although long-term amiodarone therapy is usually successful, substantial side effects include pulmonary fibrosis, hypothyroidism, liver toxicity, and corneal deposits.

Although several $\beta$-blockers decrease susceptibility to VF, most of the studies have focused on propranolol [71]. In a canine study [72] $\beta$-blocker drugs increased the fibrillation threshold 6-fold under ischemic and non-ischemic conditions. The improvement was greater with the use of more potent $\beta$-blockers and those that antagonized both the $\beta 1$ and $\beta 2$ receptors. It was shown that propranolol decreases sympathetic outflow more than does metoprolol [73]. The lipophilic nature of propranolol enables active penetration of the central nervous system and the blockade of central and pre-junctional receptors in addition to peripheral $\beta$ receptors [74,75]. Propranolol may effectively suppress an IVF episode even when metoprolol has failed [71]. Therefore, propranolol is the preferred $\beta$-blocker, pending further clinical studies. Tsagalou et al. [71] have suggested that the combination of amiodarone and propranolol improves survival rates and may be the mainstay of therapy in managing electrical IVF storm.

\begin{tabular}{|c|l|}
\hline S No & Criteria for quinidine therapy in IVF survivors \\
\hline 1 & Diagnosis of IVF with or without Brugada syndrome. \\
\hline 2 & Inducible VF in the absence of drugs with programmed ventricular stimulation. \\
\hline 3 & No-inducible arrhythmias during oral quinidine therapy despite a very aggressive protocol of ventricular stimulation. \\
\hline 4 & Informed consent by a patient who is well informed of the risk and benefits of ICD and quinidine therapy for this disease. \\
\hline 5 & $\begin{array}{l}\text { Repeated assertion of drug compliance during long-term follow-up (compliance is assessed with quinidine serum levels and quinidine-effect on the QT } \\
\text { interval). }\end{array}$ \\
\hline
\end{tabular}

Table 2: Criteria for quinidine therapy in IVF survivors. 
Radiofrequency catheter ablation: Catheter-based radiofrequency ablation of the triggering focus is now an accepted mode of therapy for IVF. The optimal timing for the electrophysiologic mapping and ablation procedure is when the patient has frequent PVCs. The origin of the PVCs is localized by mapping the earliest site of electrical activity and/or pace mapping. Purkinje origin is identified by the Purkinje potential, a sharp spike of less than $10 \mathrm{~ms}$ duration, occurring before the PVC. Radiofrequency ablation has been used primarily to treat patients with implanted ICDs who are receiving multiple ICD shocks because of arrhythmic storms [32,76,77]. The first successful ablation was reported by Aizawa in 1992 [76] whereas relatively large series have been reported by others $[32,33,58]$. The series of Haissaguerre $[32,33]$ and Noda and Shimizu [58] differ in the site of origin of the targeted arrhythmias: Noda and Shimizu targeted polymorphic VT originating from the RVOT [58]. In contrast, $85 \%$ of the polymorphic ventricular arrhythmias ablated by Haissaguerre et al. [32] were mapped to the Purkinje system in the right or left ventricle while the site of origin of the VF was in the RVOT in only 4 (15\%) patients. An acute successful ablation was achieved in all cases while 24 patients (89\%) had no recurrence of VF without drug during follow-up. Such favorable results do certainly stimulate adopting such a curative option for treating patients with IVF. However, since the etiology of IVF is unknown, at this moment it is hard to understand that this is a focal disease.

Implantable cardioverter-defibrillator: An implantable cardioverter-defibrillator (ICD) is the preferred therapeutic modality in most survivors of SCD. An ICD shock does certainly terminate an episode of spontaneous or induced IVF. This change in practice is based upon improvements in device technology, clinical trials demonstrating improved outcomes with an ICD compared to pharmacological therapy, and concerns about the toxicity associated with antiarrhythmic drugs. No doubt that ICD offers the most effective therapy for preventing arrhythmic death in IVF. Indeed, ICD implantation is considered the only effective therapy for IVF by most authors. However, the complication rate of the implantation procedure has also to be considered. In the AVID trial, a large multicenter study of ICD implantation for malignant ventricular arrhythmias in patients with organic heart disease [78], the risk of adverse events serious enough to warrant re-intervention, was $12 \%[79,80]$. Considering that an ICD terminates episodes of IVF but does not prevent arrhythmias, patients who have frequent symptoms or device discharges from recurrent arrhythmias may benefit from adjunctive anti-arrhythmic drug therapy, usually beginning with empiric amiodarone. Such drug therapy, by reducing the frequency of appropriate shocks, can improve the patient's quality of life. Anti-arrhythmic drugs, again beginning with empiric amiodarone, are also indicated in SCD survivors who are not candidates for or refuse an ICD.

\section{Conclusion}

In some selected patients, antiarrhythmic drug treatment is still an efficient approach, but predicting which patients will respond positively to drug treatment is often hampered by the absence of a reliable parameter to predict a favourable outcome. The therapy of IVF with EPS-guided quinidine may be implemented after demonstrating that VF is no longer inducible after quinidine therapy. Drug therapy in ICD patients usually begins with empiric amiodarone, or quinidine therapy. Such therapy, by reducing the frequency of appropriate shocks, can improve the patient's quality of life.

ICD therapy is the treatment of choice for patients with both primary and secondary prevention with the role of antiarrhythmic therapy aimed at reducing the number of recurrences. Implantable devices do not prevent arrhythmias, thus, patients who have frequent symptoms or device discharges from recurrent arrhythmias may benefit from adjunctive anti-arrhythmic drug therapy. Secondary and primary prevention trials have demonstrated the superiority of ICD compared with antiarrhythmic medication in preventing death. Although, ICD therapy represents the gold standard treatment for this condition the underlying substrate for the arrhythmia is unchanged by this form of therapy. Therefore, an antiarrhythmic drug is needed in this case in order to modify the arrhythmic substrate in case of relatively frequent episodes of VF. Considering that the trigger for VF is ventricular ectopy in the majority of patients, ablation of this trigger lead to abolition of VF in many cases. Therefore, catheter ablation is an accepted treatment for a number of patients with IVF. The Purkinje network is critical in the triggering and maintenance of VF, thus, catheter ablation targeting the PVCs or Purkinje potentials responsible for triggering VF was shown to be both possible and efficacious in IVF. Although the longterm results are awaited, the short-term results are very encouraging, and the procedure appears robust as it is being repeated by a number of different groups around the world. Long-term follow-up studies are required to demonstrate whether ablation of the trigger results in a definitive cure for these patients. In the meanwhile, yes there is still a place for pharmacological treatment in the therapeutic armamentarium of IVF in carefully selected, individually well documented patients.

\section{References}

1. Dock W (1929) Transitory ventricular fibrillation as a cause of syncope and its prevention by quinidine sulfate. Am Heart J 4: 709-714.

2. Belhassen B, Shapira I, Shoshani D, Paredes A, Miller H, Laniado S (1987) Idiopathic ventricular fibrillation: inducibility and beneficial effects of class I antiarrhythmic agents. Circulation 75: 809-816.

3. Viskin S, Belhassen B (1990) Idiopathic ventricular fibrillation. See comment in PubMed Commons below Am Heart J 120: 661-671.

4. Leenhardt A, Glaser E, Burguera M, Narnberg M, Maison-Blanche P, et al. (1994) Short-coupled variant of torsade de pointes. A new electrocardiographic entity in the spectrum of idiopathic ventricular tachyarrhythmias. See commen in PubMed Commons below Circulation 89: 206-215.

5. Viskin S, Lesh MD, Eldar M, Fish R, Setbon I, et al. (1997) Mode of onset of malignant ventricular arrhythmias in idiopathic ventricular fibrillation. See comment in PubMed Commons below J Cardiovasc Electrophysiol 8: 11151120.

6. Haissaguerre M, Extramiana F, Hocini M, Cauchemez B, Jais P, et al. (2003) Mapping and ablation of ventricular fibrillation associated with long-QT and Brugada syndromes. See comment in PubMed Commons below Circulation 108: 925-928.

7. Jervell A, Lange-Nielsen $F$ (1957) Congenital deaf-mutism, functional heart disease with prolongation of the Q-T interval and sudden death. See comment in PubMed Commons below Am Heart J 54: 59-68.

8. Romano C, Gemme G, Pongiglione R (1963) [Rare Cardiac Arrythmias Of The Pediatric Age li. Syncopal Attacks Due To Paroxysmal Ventricular Fibrillation. (Presentation Of 1st Case In Italian Pediatric Literature)]. See comment in PubMed Commons below Clin Pediatr (Bologna) 45: 656-683.

9. Ward OC (1964) A New Familial Cardiac Syndrome In Children. See comment in PubMed Commons below J Ir Med Assoc 54: 103-106.

10. Leenhardt A, Lucet V, Denjoy I, Grau F, Ngoc DD, et al. (1995) Catecholaminergic polymorphic ventricular tachycardia in children. A 7-year follow-up of 21 patients. See comment in PubMed Commons below Circulation 91: 1512-1519.

11. APONTE GE (1960) The enigma of "bangungut". See comment in PubMed Commons below Ann Intern Med 52: 1258-1263.

12. Brugada P, Brugada J (1992) Right bundle branch block, persistent ST segment elevation and sudden cardiac death: a distinct clinical and electrocardiographic syndrome. A multicenter report. See comment in PubMed Commons below J Am Coll Cardiol 20: 1391-1396. 
Citation: Centurión OA (2014) Therapeutic Management in the Idiopathic Ventricular Fibrillation: Is there Still a Place for Pharmacological Treatment? J Bioequiv Availab 6: 128-133. doi:10.4172/jbb.1000192

13. Viskin S, Fish R, Eldar M, Zeltser D, Lesh MD, et al. (2000) Prevalence of the Brugada sign in idiopathic ventricular fibrillation and healthy controls. See comment in PubMed Commons below Heart 84: 31-36.

14. Nademanee K, Veerakul G, Nimmannit S, Chaowakul V, Bhuripanyo K, et al (1997) Arrhythmogenic marker for the sudden unexplained death syndrome in Thai men. See comment in PubMed Commons below Circulation 96: 25952600.

15. Gaita F, Giustetto C, Bianchi F, Wolpert C, Schimpf R, et al. (2003) Short QT Syndrome: a familial cause of sudden death. See comment in PubMed Commons below Circulation 108: 965-970.

16. Gussak I, Brugada P, Brugada J, Wright RS, Kopecky SL, et al. (2000) Idiopathic short QT interval: a new clinical syndrome? See comment in PubMed Commons below Cardiology 94: 99-102.

17. Schimpf R, Bauersfeld U, Gaita F, Wolpert C (2005) Short QT syndrome: successful prevention of sudden cardiac death in an adolescent by implantable cardioverter-defibrillator treatment for primary prophylaxis. Heart Rhythm 2 : 416-417.

18. Viskin S, Zeltser D, Ish-Shalom M, et al. (2004) Is idiopathic ventricular fibrillation a short QT syndrome? Comparison of QT intervals of patients with idiopathic ventricular fibrillation and healthy controls. Heart Rhythm 1: 587-591.

19. Chen Q, Kirsch GE, Zhang D, Brugada R, Brugada J, et al. (1998) Genetic basis and molecular mechanism for idiopathic ventricular fibrillation. See comment in PubMed Commons below Nature 392: 293-296.

20. Bellocq C, van Ginneken AC, Bezzina CR, Alders M, Escande D, et al. (2004) Mutation in the KCNQ1 gene leading to the short QT-interval syndrome. See comment in PubMed Commons below Circulation 109: 2394-2397.

21. Brugada R, Hong K, Dumaine R, Cordeiro J, Gaita F, et al. (2004) Sudden death associated with short-QT syndrome linked to mutations in HERG. See comment in PubMed Commons below Circulation 109: 30-35.

22. Priori SG, Pandit SV, Rivolta I, Berenfeld O, Ronchetti E, et al. (2005) A nove form of short QT syndrome (SQT3) is caused by a mutation in the KCNJ2 gene. See comment in PubMed Commons below Circ Res 96: 800-807.

23. Hong K, Brugada J, Oliva A, Berruezo-Sanchez A, Potenza D, et al. (2004) Value of electrocardiographic parameters and ajmaline test in the diagnosis of Brugada syndrome caused by SCN5A mutations. See comment in PubMed Commons below Circulation 110: 3023-3027.

24. Rolf S, Bruns HJ, Wichter T, Kirchhof P, Ribbing M, et al. (2003) The ajmaline challenge in Brugada syndrome: diagnostic impact, safety, and recommended protocol. See comment in PubMed Commons below Eur Heart J 24: 1104 1112 .

25. Wolpert C, Echternach C, Veltmann C, Antzelevitch C, Thomas GP, et al. (2005) Intravenous drug challenge using flecainide and ajmaline in patients with Brugada syndrome. See comment in PubMed Commons below Heart Rhythm 2: 254-260.

26. Meregalli PG, Ruijter JM, Hofman N, Bezzina CR, Wilde AA, et al. (2006) Diagnostic value of flecainide testing in unmasking SCN5A-related Brugada syndrome. See comment in PubMed Commons below J Cardiovasc Electrophysiol 17: 857-864

27. Priori SG, Napolitano C, Schwartz PJ, Bloise R, Crotti L, et al. (2000) The elusive link between LQT3 and Brugada syndrome: the role of flecainide challenge. See comment in PubMed Commons below Circulation 102: 945947.

28. Chinushi M, Aizawa Y, Ogawa Y, Shiba M, Takahashi K (1997) Discrepant drug action of disopyramide on ECG abnormalities and induction of ventricular arrhythmias in a patient with Brugada syndrome. See comment in PubMed Commons below J Electrocardiol 30: 133-136.

29. Sangwatanaroj S, Prechawat S, Sunsaneewitayakul B, Sitthisook S, Tosukhowong P, et al. (2001) New electrocardiographic leads and the procainamide test for the detection of the Brugada sign in sudden unexplained death syndrome survivors and their relatives. See comment in PubMed Commons below Eur Heart J 22: 2290-2296.

30. Hong K, Bjerregaard P, Gussak I, Brugada R (2005) Short QT syndrome and atrial fibrillation caused by mutation in $\mathrm{KCNH} 2$. See comment in PubMed Commons below J Cardiovasc Electrophysiol 16: 394-396.

31. Belhassen B, Viskin S (1993) Idiopathic ventricular tachycardia and fibrillation.
See comment in PubMed Commons below J Cardiovasc Electrophysiol 4: 356 368.

32. Haissaguerre M, Shoda M, Jais P, Nogami A, Shah DC, et al. (2002) Mapping and ablation of idiopathic ventricular fibrillation. See comment in PubMed Commons below Circulation 106: 962-967.

33. Haissaguerre M, Shah DC, Jais P, Shoda M, Kautzner J, et al. (2002) Role of Purkinje conducting system in triggering of idiopathic ventricular fibrillation. See comment in PubMed Commons below Lancet 359: 677-678.

34. Champagne J, Geelen P, Philippon F, Brugada P (2005) Recurrent cardiac events in patients with idiopathic ventricular fibrillation, excluding patients with the Brugada syndrome. See comment in PubMed Commons below BMC Med 3: 1 .

35. Viskin S, Belhassen B (1998) Polymorphic ventricular tachyarrhythmias in the absence of organic heart disease: classification, differential diagnosis, and implications for therapy. See comment in PubMed Commons below Prog Cardiovasc Dis 41: 17-34.

36. Pasquie JL, Sanders P, Hocini M, Hsu LF, Scavee C, et al. (2004) Fever as a precipitant of idiopathic ventricular fibrillation in patients with normal hearts. See comment in PubMed Commons below J Cardiovasc Electrophysiol 15: 1271-1276.

37. Takagi M, Aihara N, Takaki H, Taguchi A, Shimizu W, et al. (2000) Clinica characteristics of patients with spontaneous or inducible ventricular fibrillation without apparent heart disease presenting with $\mathrm{J}$ wave and ST segment elevation in inferior leads. See comment in PubMed Commons below $J$ Cardiovasc Electrophysiol 11: 844-848.

38. Shimizu W, Horie M, Ohno S, Takenaka K, Yamaguchi M, et al. (2004) Mutation site-specific differences in arrhythmic risk and sensitivity to sympathetic stimulation in the LQT1 form of congenital long QT syndrome: multicenter study in Japan. See comment in PubMed Commons below J Am Coll Cardiol 44: 117-125.

39. Yan GX, Antzelevitch C (1998) Cellular basis for the normal $T$ wave and the electrocardiographic manifestations of the long-QT syndrome. See comment in PubMed Commons below Circulation 98: 1928-1936.

40. Castro Hevia J, Antzelevitch C, TornÃ@s BÃ $j$ rzaga F, Dorantes SÃ $i n c h e z ~ M$ Dortic $\tilde{A}^{3}$ s Balea $F$, et al. (2006) Tpeak-Tend and Tpeak-Tend dispersion as risk factors for ventricular tachycardia/ventricular fibrillation in patients with the Brugada syndrome. See comment in PubMed Commons below J Am Coll Cardiol 47: 1828-1834.

41. Noda T, Shimizu W, Satomi K, Suyama K, Kurita T, et al. (2004) Classification and mechanism of Torsade de Pointes initiation in patients with congenital long QT syndrome. See comment in PubMed Commons below Eur Heart $J$ 25: $2149-2154$

42. Viskin S, Alla SR, Barron HV, Heller K, Saxon L, et al. (1996) Mode of onset of torsade de pointes in congenital long QT syndrome. See comment in PubMed Commons below J Am Coll Cardiol 28: 1262-1268.

43. Belhassen B, Pelleg A, Miller HI, Laniado S (1981) Serial electrophysiological studies in a young patient with recurrent ventricular fibrillation. See comment in PubMed Commons below Pacing Clin Electrophysiol 4: 92-99.

44. Belhassen B, Viskin S, Fish R, Glick A, Setbon I, et al. (1999) Effects of electrophysiologic-guided therapy with Class IA antiarrhythmic drugs on the long-term outcome of patients with idiopathic ventricular fibrillation with or without the Brugada syndrome. See comment in PubMed Commons below J Cardiovasc Electrophysiol 10: 1301-1312.

45. Gaita F, Giustetto C, Bianchi F, Schimpf R, Haissaguerre M, et al. (2004) Short QT syndrome: pharmacological treatment. See comment in PubMed Commons below J Am Coll Cardiol 43: 1494-1499.

46. Gussak I, Bjerregaard P (2005) Short QT syndrome--5 years of progress. See comment in PubMed Commons below J Electrocardiol 38: 375-377.

47. Brugada P, Geelen P, Brugada R, Mont L, Brugada J (2001) Prognostic value of electrophysiologic investigations in Brugada syndrome. J Cardiovasc Electrophysiol 12: 1004-1007.

48. Boersma LV, Jaarsma W, Jessurun ER, Van Hemel NH, Wever EF (2001) Brugada syndrome: a case report of monomorphic ventricular tachycardia. See comment in PubMed Commons below Pacing Clin Electrophysiol 24: 112-115.

49. Dinckal MH, Davutoglu V, Akdemir I, Soydinc S, Kirilmaz A, Aksoy M (2003) Incessant monomorphic ventricular tachycardia during febrile illness in a patient with Brugada syndrome: fatal electrical storm. Europace 5: 257-261. 
Citation: Centurión OA (2014) Therapeutic Management in the Idiopathic Ventricular Fibrillation: Is there Still a Place for Pharmacological Treatment? J Bioequiv Availab 6: 128-133. doi:10.4172/jbb.1000192

50. Mok NS, Chan NY (2004) Brugada syndrome presenting with sustained monomorphic ventricular tachycardia. See comment in PubMed Commons below Int J Cardiol 97: 307-309.

51. Sastry BK, Narasimhan C, Soma Raju B (2001) Brugada syndrome with monomorphic ventricular tachycardia in a one-year-old child. See comment in PubMed Commons below Indian Heart J 53: 203-205.

52. Shimada M, Miyazaki T, Miyoshi S, Soejima K, Hori S, et al. (1996) Sustained monomorphic ventricular tachycardia in a patient with Brugada syndrome. See comment in PubMed Commons below Jpn Circ J 60: 364-370.

53. Viskin S, Belhassen B (1995) Clinical problem-solving. When you only live twice. See comment in PubMed Commons below N Engl J Med 332: 1221 1225.

54. Brugada P, Green M, Abdollah H, Wellens HJ (1984) Significance of ventricular arrhythmias initiated by programmed ventricular stimulation: the importance of the type of ventricular arrhythmia induced and the number of premature stimuli required. See comment in PubMed Commons below Circulation 69: 87-92.

55. Morady F, DiCarlo LA Jr, Baerman JM, de Buitleir M (1986) Comparison of coupling intervals that induce clinical and nonclinical forms of ventricular tachycardia during programmed stimulation. See comment in PubMed Commons below Am J Cardiol 57: 1269-1273.

56. Stevenson WG, Brugada P, Waldecker B, Zehender M, Wellens HJ (1986) Can potentially significant polymorphic ventricular arrhythmias initiated by programmed stimulation be distinguished from those that are nonspecific? See comment in PubMed Commons below Am Heart J 111: 1073-1080.

57. Belhassen B, Shapira I, Sheps D, Laniado S (1990) Programmed ventricular stimulation using up to two extrastimuli and repetition of double extrastimulation for induction of ventricular tachycardia: a new highly sensitive and specific protocol. See comment in PubMed Commons below Am J Cardiol 65: 615-622.

58. Noda T, Shimizu W, Taguchi A, Aiba T, Satomi K, et al. (2005) Malignant entity of idiopathic ventricular fibrillation and polymorphic ventricular tachycardia initiated by premature extrasystoles originating from the right ventricular outflow tract. See comment in PubMed Commons below J Am Coll Cardiol 46 1288-1294.

59. Wever EF, Robles de Medina EO (2004) Sudden death in patients without structural heart disease. See comment in PubMed Commons below J Am Coll Cardiol 43: 1137-1144.

60. Moe T (1949) Morgagni-Adams-Stokes attacks caused by transient recurren ventricular fibrillation in a patient without apparent heart disease. Am Heart $J$ 37: 811-818

61. Kontny F, Dale J (1990) Self-terminating idiopathic ventricular fibrillation presenting as syncope: a 40-year follow-up report. See comment in PubMed Commons below J Intern Med 227: 211-213.

62. Belhassen B (2004) A 25-year control of idiopathic ventricular fibrillation with electrophysiologic-guided antiarrhythmic drug therapy. See comment in PubMed Commons below Heart Rhythm 1: 352-354.

63. Belhassen B, Viskin S (1998) Management of idiopathic ventricula fibrillation: implantable defibrillators? antiarrhythmic drugs? Ann Noninvasive Electrocardiol 3: 125-128

64. Haghjoo M, Arya A, Heidari A, Sadr-Ameli MA (2005) Suppression of electrical storm by oral quinidine in a patient with Brugada syndrome. See comment in PubMed Commons below J Cardiovasc Electrophysiol 16: 674.

65. Marquez MF, Rivera J, Hermosillo AG, Iturralde P, ColÃn L, et al. (2005) Arrhythmic storm responsive to quinidine in a patient with Brugada syndrome and vasovagal syncope. See comment in PubMed Commons below Pacing Clin Electrophysiol 28: 870-873.
66. Kodama I, Kamiya K, Honjo H, Toyama J (1996) Acute and chronic effects of amiodarone on mammalian ventricular cells. See comment in PubMed Commons below Jpn Heart J 37: 719-730.

67. Du XJ, Esler MD, Dart AM (1995) Sympatholytic action of intravenous amiodarone in the rat heart. See comment in PubMed Commons below Circulation 91: 462-470.

68. Kudenchuk PJ, Cobb LA, Copass MK, Cummins RO, Doherty AM, et al (1999) Amiodarone for resuscitation after out-of-hospital cardiac arrest due to ventricular fibrillation. See comment in PubMed Commons below N Engl J Med 341: 871-878.

69. Levine JH, Massumi A, Scheinman MM, Winkle RA, Platia EV, et al. (1996) Intravenous amiodarone for recurrent sustained hypotensive ventricular tachyarrhythmias. Intravenous Amiodarone Multicenter Trial Group. J Am Coll Cardiol 27: 67-75.

70. Vassallo P, Trohman RG (2007) Prescribing amiodarone: an evidence-based review of clinical indications. See comment in PubMed Commons below JAMA 298: 1312-1322.

71. Tsagalou EP, Kanakakis J, Rokas S, Anastasiou-Nana MI (2005) Suppression by propranolol and amiodarone of an electrical storm refractory to metoprolo and amiodarone. See comment in PubMed Commons below Int J Cardiol 99 341-342.

72. Anderson JL, Rodier HE, Green LS (1983) Comparative effects of betaadrenergic blocking drugs on experimental ventricular fibrillation threshold. See comment in PubMed Commons below Am J Cardiol 51: 1196-1202.

73. Newton GE, Parker JD (1996) Cardiac sympathetic responses to acute vasodilation. Normal ventricular function versus congestive heart failure. See comment in PubMed Commons below Circulation 94: 3161-3167.

74. Bristow MR, Ginsburg R, Umans V, Fowler M, Minobe W, et al. (1986) Beta 1- and beta 2-adrenergic-receptor subpopulations in nonfailing and failing human ventricular myocardium: coupling of both receptor subtypes to muscle contraction and selective beta 1-receptor down-regulation in heart failure. See comment in PubMed Commons below Circ Res 59: 297-309.

75. Billman GE, Castillo LC, Hensley J, Hohl CM, Altschuld RA (1997) Beta2adrenergic receptor antagonists protect against ventricular fibrillation: in vivo and in vitro evidence for enhanced sensitivity to beta2-adrenergic stimulation in animals susceptible to sudden death. See comment in PubMed Commons below Circulation 96: 1914-1922.

76. Mok NS, Chan NY, Chiu AC (2004) Successful use of quinidine in treatment of electrical storm in Brugada syndrome. See comment in PubMed Commons below Pacing Clin Electrophysiol 27: 821-823.

77. Aizawa Y, Tamura M, Chinushi M, Niwano S, Kusano Y, et al. (1992) An attempt at electrical catheter ablation of the arrhythmogenic area in idiopathic ventricular fibrillation. See comment in PubMed Commons below Am Heart $\mathrm{J}$ 123: $257-260$.

78. Kusano KF, Yamamoto M, Emori T, Morita H, Ohe T (2000) Successful catheter ablation in a patient with polymorphic ventricular tachycardia. See comment in PubMed Commons below J Cardiovasc Electrophysiol 11: 682-685.

79. (1997) A comparison of antiarrhythmic-drug therapy with implantable defibrillators in patients resuscitated from near-fatal ventricular arrhythmias. The Antiarrhythmics versus Implantable Defibrillators (AVID) Investigators. See comment in PubMed Commons below N Engl J Med 337: 1576-1583.

80. Kron J, Herre J, Renfroe EG, Rizo-Patron C, Raitt M, et al. (2001) Leadand device-related complications in the antiarrhythmics versus implantable defibrillators trial. See comment in PubMed Commons below Am Heart J 141 . 92-98. 